\section{Immediate pars plana vitrectomy for dislocated intravitreal lens fragments during cataract surgery}

TYY Lai ${ }^{1}$, AKH Kwok², Y-S Yeung ${ }^{1}$, KYW Kwan ${ }^{3}$, DCF Woo ${ }^{3}, \mathrm{KSC}$ Yuen $^{4}$ and AVP Loo ${ }^{5}$

secondary glaucoma and cystoid macular oedema after surgery.

Eye (2005) 19, 1157-1162. doi:10.1038/sj.eye.6701708; published online 24 September 2004

Keywords: phacoemulsification; dropped nucleus; retained lens fragments; pars plana vitrectomy; phacofragmentation; immediate vitrectomy for dislocated lens fragments at the same sitting of phacoemulsification surgery were reviewed. Data including patients' demographics, preoperative and postoperative vision, risk factors for lens fragment dislocation, and intraoperative and postoperative complications were recorded. Results The mean follow-up period of the patients was 12.3 months (range, 3-47 months). The median preoperative visual acuity was 6/90 (range, LP to 6/15). The median final postoperative visual acuity was 6/18 (range, NLP to 6/9) and the mean improvement in vision after the operation was 4.5 lines. The commonest risk factors for dislocation of lens fragment were late detection of posterior capsule tear, splitting of anterior capsulorrhexis, and hard nucleus. After excluding nine eyes with other pre-existing ocular comorbidities, $10(50 \%)$ eyes had a final visual acuity of $6 / 12$ or better. Complications after surgery included three $(\mathbf{1 0 \%})$ cases of retinal detachment and one $(3 \%)$ patient developed epiretinal membrane. None of the patients in the study developed secondary glaucoma or cystoid macular oedema following surgery.

Conclusion Immediate vitrectomy in the same sitting of the cataract surgery is a surgical option in the management of dislocated intravitreal lens fragments when vitreoretinal support is available. Most patients achieve a good visual outcome with reduced risk of

\section{Introduction}

Dislocated lens fragment in the vitreous cavity is an uncommon event that occurs in $0.2-1.5 \%$ of cases during phacoemulsification surgery. ${ }^{1-5}$ However, such mishap is a potentially serious complication since it can lead to severe intraocular inflammation causing secondary glaucoma, vitreous opacification, cystoid macular oedema, corneal oedema, and retinal detachment. ${ }^{6-8}$ Pars plana vitrectomy has been used successfully to retrieve the retained lens fragments in order to minimise the risk of further complications. ${ }^{5-21}$ Although the optimal timing of pars plana vitrectomy remains controversial, ${ }^{7,10-14}$ histological studies have shown that inflammatory reaction is more severe with longer duration of lens fragments remaining within the eye. ${ }^{22,23}$ The performance of pars plana vitrectomy to retrieve the dislocated lens fragments at the time of cataract surgery may therefore be beneficial to minimise postoperative inflammation and its associated morbidity, as well as eliminate the need of two separate operations. We have therefore performed immediate pars plana vitrectomy at the same sitting of the cataract extraction that is complicated by dislocated lens fragments when vitreoretinal expertise is available.

The purpose of this study is to evaluate the visual outcome, risk factors of dislocated lens
${ }^{1}$ Department of

Ophthalmology and Visual

Sciences, The Chinese

University of Hong Kong

Hong Kong Eye Hospital

Hong Kong

People's Republic of China

${ }^{2}$ Department of

Ophthalmology

Hong Kong Sanatorium and

Hospital, Hong Kong

People's Republic of China

${ }^{3}$ Department of

Ophthalmology

Tung Wah Eastern Hospital

Hong Kong

People's Republic of China

${ }^{4}$ Department of

Ophthalmology and Visual

Sciences, The Chinese

University of Hong Kong

Prince of Wales Hospital

Hong Kong

People's Republic of China

${ }^{5}$ Department of

Ophthalmology

Tseung Kwan O Hospital

Hong Kong

People's Republic of China

Correspondence:

AKH Kwok

Department of

Ophthalmology

Hong Kong Sanatorium and

Hospital, 2 Village Road

Happy Valley, Hong Kong

Tel: + 85228358890

Fax: + 85228927510

E-mail: alvinkwok@hksh.com

Received: 17 May 2004

Accepted: 20 July 2004

Published online:

24 September 2004

Financial or proprietary

interest: Nil.

Financial support: Nil. 
fragments, and perioperative complications of pars plana vitrectomy for dislocated lens fragment at the same sitting with the cataract surgery.

\section{Patients and methods}

A retrospective review of patient records from July 1997 to June 2003 in five ophthalmic centres serving a population of five million people in Hong Kong was performed. Those who underwent instantaneous primary pars plana vitrectomy for dislocated lens fragments during cataract surgery were included in the final analysis. Cases with traumatic or spontaneous dislocation of lens before surgery, and follow-up period of less than 3 months were excluded from the study. Six of the cases in this study have been reported in our paper previously. ${ }^{21}$

All patients received standard three-port pars plana vitrectomy at the same sitting of the cataract operation that was complicated by lens fragments found to have dislocated into the vitreous cavity. In certain cases, phacofragmentation and/or heavy perfluorocarbon liquid were used. The following information was particularly noted for each patient: age, gender, visual acuity before cataract operation, risk factors for lens dislocation, size of the dislocated lens fragment, lens status after pars plana vitrectomy, perioperative complications, and final visual acuity. Visual acuity was measured by refraction or with pin-hole by certified optometrist using a Snellen chart and converted to a line score for calculating the visual changes before and after surgery. In patients with visual acuity of $6 / 60$ or worse, an optotype of $6 / 60$ size was presented closer to the patient and measurement of visual acuity was then extrapolated.

\section{Results}

A total of 29 eyes of 29 patients were included in the study (Table 1). The mean age of the patients was 73.7 years (range, $57-84$ years). There were 18 male (62\%) and 11 female (38\%) patients. All eyes underwent phacoemulsification cataract surgery. The mean follow-up period after surgery was 12.3 months (range, 3-47 months).

Nine (31\%) patients had pre-existing eye diseases other than cataract that limited the vision of patients. These included three $(10 \%)$ patients with myopic maculopathy, three $(10 \%)$ patients with disciform age-related maculopathy, two (7\%) patients with glaucoma and one (3\%) patient with severe exudative diabetic maculopathy. The median preoperative visual acuity of the 29 patients was 6/90 (range, LP to 6/15).
Risk factors for dislocation of lens fragments during cataract operation were shown in Table 2. The most common risk factors included late detection of posterior capsular tear (16 cases), split in the anterior capsulorrhexis (three cases), and hard nucleus (three cases). The size of the lens fragments dropped was estimated by the surgeon and the number of cases with dropped nucleus size of less than $30 \%$, between 30 and $60 \%$, and greater than $60 \%$ were two, 12 , and seven respectively. Data were not available in eight patients. Two patients were planned for general anaesthesia, while the remaining 27 patients were operated under retrobulbar anaesthesia. Conversion to general anaesthesia for the subsequent pars plana vitrectomy was not required in any patient of the retrobulbar anaesthesia group. Removal of lens fragment during pars plana vitrectomy was performed by using vitreous cutter, phacofragmentation, and limbal delivery in 22,11 , and six eyes, respectively. Perfluorocarbon heavy liquid was used in eight $(28 \%)$ cases. Two $(7 \%)$ cases had intraoperative complications due to sclerotomy-related retinal tears. Endolaser photocoagulation alone was performed in one case and endolaser photocoagulation together with injection of gas was performed in the other. Both cases did not develop any complications subsequently.

The median final postoperative visual acuity was $6 / 18$ (range, NLP to 6/9). The mean improvement in visual acuity was 4.5 lines (range, -2-11 lines). Of the patients, $20(69 \%)$ had improvements of 2 or more lines. Seven patients $(24 \%)$ had a final acuity of within 1 line while two patients $(7 \%)$ lost 2 lines of visual acuity following operation. Of the 29 eyes, $10(34 \%)$ had a final visual acuity of $6 / 12$ or better. A total of $14(48 \%)$ eyes had a final visual acuity of $6 / 15$ or better and $17(59 \%)$ having final visual acuity of $6 / 18$ or better. After excluding nine eyes with pre-existing ocular diseases that compromised the postoperative vision, $10(50 \%)$ patients had a final visual acuity of $6 / 12$ or better. Eight $(28 \%)$ of the 29 patients had a final visual acuity of $6 / 60$ or worse postoperatively. The reasons of poor visual acuity of $6 / 60$ or worse included preoperative disciform age-related maculopathy (two cases), myopic maculopathy (two cases) and severe exudative diabetic maculopathy (one case); as well as postoperative development of retinal detachment (two cases) and epiretinal membrane formation (one case).

In terms of postvitrectomy lens status, 21 (72\%) of the 29 patients had the posterior chamber intraocular lens (PCIOL) implanted in the sulcus, three patients (10\%) received scleral-fixated intraocular lens, two $(7 \%)$ patients had anterior chamber intraocular lens (ACIOL) implanted, and three patients $(10 \%)$ were left aphakic due to poor pre-existing eye condition. In patients who 
Table 1 Data of 29 eyes that underwent immediate pars plana vitrectomy for retained lens fragments following cataract surgery

\begin{tabular}{|c|c|c|c|c|c|c|c|c|c|}
\hline $\begin{array}{l}\text { Patient } \\
\text { No }\end{array}$ & Sex & $\begin{array}{c}\text { Age } \\
\text { (years) }\end{array}$ & $\begin{array}{c}\text { Follow-up } \\
\text { (months) }\end{array}$ & $\begin{array}{l}\text { Preop. } \\
\text { BCVA }\end{array}$ & $\begin{array}{c}\text { Postop. } \\
\text { BCVA }\end{array}$ & $\begin{array}{c}\text { Lines of } \\
\text { BCVA } \\
\text { improvement }\end{array}$ & $\begin{array}{l}\text { Postop. } \\
\text { lens } \\
\text { status }\end{array}$ & $\begin{array}{l}\text { Pre-existing } \\
\text { eye disease }\end{array}$ & Complications \\
\hline 1 & M & 65 & 7 & $\mathrm{CF}$ & $6 / 9$ & 11 & PCIOL & Nil & Nil \\
\hline 2 & $\mathrm{M}$ & 84 & 47 & $6 / 60$ & $6 / 18$ & 5 & PCIOL & Nil & Nil \\
\hline 3 & $\mathrm{~F}$ & 80 & 29 & $6 / 60$ & $6 / 30$ & 3 & PCIOL & Glaucoma & Nil \\
\hline 4 & $\mathrm{~F}$ & 64 & 38 & $\mathrm{HM}$ & NLP & -2 & Aphakic & AMD & $\begin{array}{l}\text { Retinal detachment } \\
+ \text { Phthisis }\end{array}$ \\
\hline 5 & $\mathrm{M}$ & 80 & 28 & LP & $\mathrm{CF}$ & 2 & Aphakic & Myopic maculopathy & Nil \\
\hline 6 & M & 79 & 3 & $\mathrm{CF}$ & $6 / 120$ & 1 & ACIOL & Myopic maculopathy & Nil \\
\hline 7 & M & 81 & 3 & $\mathrm{HM}$ & $6 / 15$ & 10 & PCIOL & Nil & Nil \\
\hline 8 & $\mathrm{~F}$ & 78 & 7 & $6 / 120$ & $6 / 30$ & 5 & PCIOL & Nil & $\begin{array}{l}\text { Intraoperative retinal } \\
\text { tear }\end{array}$ \\
\hline 9 & M & 79 & 3 & $6 / 60$ & $6 / 12$ & 7 & PCIOL & Nil & Nil \\
\hline 10 & $\mathrm{~F}$ & 70 & 4 & $6 / 120$ & $6 / 15$ & 8 & PCIOL & Nil & Nil \\
\hline 11 & $\mathrm{~F}$ & 83 & 12 & $6 / 120$ & $6 / 18$ & 7 & PCIOL & Nil & Nil \\
\hline 12 & M & 69 & 8 & $6 / 120$ & $6 / 15$ & 8 & PCIOL & Nil & Nil \\
\hline 13 & $\mathrm{M}$ & 76 & 5 & $6 / 30$ & $6 / 18$ & 2 & PCIOL & Nil & Retinal detachment \\
\hline 14 & M & 81 & 4 & $6 / 60$ & $6 / 15$ & 6 & PCIOL & Myopic maculopathy & $\begin{array}{l}\text { Intraoperative retinal } \\
\text { tear }\end{array}$ \\
\hline 15 & M & 72 & 3 & $6 / 120$ & $6 / 9$ & 10 & PCIOL & Nil & Nil \\
\hline 16 & $\mathrm{~F}$ & 79 & 6 & $\mathrm{HM}$ & $\mathrm{CF}$ & 1 & Aphakic & AMD & Nil \\
\hline 17 & M & 68 & 3 & $6 / 15$ & $6 / 9$ & 2 & PCIOL & Nil & Nil \\
\hline 18 & $\mathrm{~F}$ & 66 & 20 & $6 / 60$ & $6 / 60$ & 0 & SFIOL & Nil & Epiretinal membrane \\
\hline 19 & M & 68 & 3 & $6 / 120$ & $6 / 9$ & 10 & SFIOL & Nil & Nil \\
\hline 20 & M & 67 & 4 & $6 / 60$ & $6 / 12$ & 7 & PCIOL & Nil & Choroidal detachment \\
\hline 21 & M & 79 & 12 & $6 / 90$ & $6 / 60$ & 1 & ACIOL & AMD & Nil \\
\hline 22 & $\mathrm{~F}$ & 80 & 3 & $6 / 60$ & $6 / 60$ & 0 & PCIOL & Exudative DR & Nil \\
\hline 23 & $\mathrm{~F}$ & 71 & 7 & $6 / 24$ & $6 / 36$ & -2 & PCIOL & Glaucoma & Nil \\
\hline 24 & M & 71 & 5 & $6 / 36$ & $6 / 12$ & 5 & SFIOL & Nil & Nil \\
\hline 25 & $\mathrm{~F}$ & 72 & 16 & $6 / 120$ & $\mathrm{CF}$ & -1 & PCIOL & Nil & $\begin{array}{l}\text { Retinal detachment } \\
\text { + hypotony }\end{array}$ \\
\hline 26 & $\mathrm{M}$ & 75 & 24 & $6 / 30$ & $6 / 9$ & 5 & PCIOL & Nil & Nil \\
\hline 27 & $\mathrm{~F}$ & 70 & 16 & $6 / 36$ & $6 / 9$ & 6 & PCIOL & Nil & Nil \\
\hline 28 & M & 73 & 34 & $6 / 30$ & $6 / 24$ & 1 & PCIOL & Nil & Nil \\
\hline 29 & M & 57 & 3 & $\mathrm{HM}$ & $6 / 12$ & 11 & PCIOL & Nil & Nil \\
\hline
\end{tabular}

$\mathrm{PCIOL}=$ posterior chamber IOL; $\mathrm{AMD}=$ age-related macular degeneration; $\mathrm{ACIOL}=$ anterior chamber $\mathrm{IOL} ; \mathrm{DR}=$ diabetic retinopathy; $\mathrm{SFIOL}=$ scleral-fixated IOL.

Table 2 Risk factors for retained lens fragments in 29 patients

\begin{tabular}{lc}
\hline Risk factors & No. of patients \\
\hline Late detection of PC tear & 16 \\
Split of anterior CCC & 3 \\
Hard nucleus & 3 \\
Fluctuation of anterior chamber depth & 1 \\
Small pupil & 1 \\
High myopia & 1 \\
Weak zonules & 1 \\
Posterior synechiae & 1 \\
Machine failure & 1 \\
None identified & 5 \\
\hline PC $=$ posterior capsule; $C C C=$ continuous curvilinear capsulorrhexis.
\end{tabular}

had intraocular lens implanted, the lens were implanted following intravitreal fragments removal at the end of the same operation.
Five (17\%) patients had postoperative complications after pars plana vitrectomy. Three patients developed macular-off rhegmatogenous retinal detachment 3-8 months postoperatively. Among these cases, one retina was reattached successfully with a final visual acuity of 6/18 following pars plana vitrectomy, fluid/gas exchange, and endolaser. The second patient developed recurrent retinal detachment with proliferative vitreoretinopathy despite repeated pars plana vitrectomy and ancillary procedures. The eye became hypotonic with a visual acuity of count finger. The third patient refused any retinal detachment surgery and the eye became phthsical with no light perception. The fourth patient developed limited self-resolving choroidal detachment with a final vision of $6 / 12$. The fifth patient developed an epiretinal membrane, which dropped the early postoperative vision of 6/18 to 6/601 year after operation. She denied further vitreous surgery. None of 
the 29 patients in the study developed chronic uveitis, secondary glaucoma, or cystoid macular oedema postoperatively. The two patients with pre-existing glaucoma did not have worsening of glaucoma during the follow-up period.

\section{Discussion}

The optimal timing of pars plana vitrectomy in the management of dislocated lens fragment complicating cataract surgery remains controversial. Several studies, concluded that the timing of vitrectomy did not affect the visual outcome in respective large series of more than 100 eyes. ${ }^{10,12,13,24}$ Another study of 89 eyes by Al-Khaier et $a l^{14}$ reported that vitrectomy after 4 weeks statistically correlated with a poor visual outcome. Nonetheless, 44-69\% of the patients achieving a final visual outcome of $6 / 12$ or better. ${ }^{10,12-14,24}$ In most of the reported series, vitreous surgeries were not performed immediately or on the same day as the cataract surgery. ${ }^{10,12,13}$ In the series by Al-Khaier et al, ${ }^{14}$ they did not report the outcome of the 10 patients that received vitrectomy on the same day.

Kim $e t a l^{8}$ reported that $75 \%$ of eight eyes operated on the same day as the cataract surgery had final vision of $6 / 9$ or better, while only $63 \%$ of the other 54 eyes operated later had final vision of $6 / 12$ or better. Tommila and Immonen ${ }^{17}$ reported that of eyes undergoing vitrectomy immediately after cataract extraction $57 \%$ of seven eyes achieved a vision of $6 / 12$ or better, compared with $78 \%$ of 16 eyes that were vitrectomised 1-7 days after cataract surgery. Terasaki $e a^{18}{ }^{18}$ reported that $75 \%$ of four eyes operated on the same day as the cataract surgery had final vision of $6 / 9$ or better, compared with $70 \%$ of the other 10 eyes operated 2-7 days after cataract surgery. ${ }^{20}$ Kageyama et $a l^{5}$ reported 17 cases of pars plana vitrectomy performed for dislocated lens fragment at the time of phacoemulsification, in which $82 \%$ of patient had a final visual acuity of $6 / 12$ or better.

Our series consists of 29 patients, to the best of our knowledge, is the largest series describing immediate pars plana vitrectomy performed for dislocated lens fragments during cataract surgery in the literature. In our study, $59 \%$ of the patients had a final visual acuity of $6 / 18$ or better, but only $34 \%$ of them achieved a final visual outcome of $6 / 12$ or better. This percentage is apparently lower compared with other published series with $41-82 \%$ of cases achieving a final visual acuity of $6 / 12$ or better, regardless of the time interval between cataract and vitreous surgery. ${ }^{5-21,24}$ This may be due to a large proportion $(31 \%)$ of our cases having pre-existing ocular diseases before cataract surgery, with an overall median preoperative visual acuity of 6/90. In the series by Kageyama et $a l_{,}^{5}$ the median preoperative visual acuity was $6 / 15$ with only $12 \%$ of cases had pre-existing ocular comorbidity. After excluding the nine cases with pre-existing ocular condition in our series, $50 \%$ of our patients had a final visual acuity of $6 / 12$ or better. Based on our study and other studies, there seems to be little difference in the final visual outcome with respect to the time of vitrectomy in managing such complication.

One of the main findings in our study is that the development of secondary glaucoma was not observed in any patients. This is in agreement with the findings of Kageyama et $a l^{5}$ and Kim et $a l^{8}$ in that none of their cases undergoing vitrectomy for dislocated lens fragments on the same day of cataract surgery developed secondary glaucoma. This is an important finding since secondary glaucoma had been reported in $5-41 \%$ in previous studies in which pars plana vitrectomy was performed later. ${ }^{6,8,10,13-15,20,21,24}$ Blodi et al ${ }^{9}$ also showed that early pars plana vitrectomy within 3 weeks decreased the rate of chronic glaucoma. Wilkinson and Green ${ }^{22}$ have shown that in 135 consecutive vitreous specimens that were obtained during vitreous surgery for retained lens material after surgery for senile cataract, no inflammatory cells were found in which vitrectomy was performed within 3 days of cataract surgery while lensinduced inflammatory reaction increased as the time interval of surgeries increased. In a clinicopathological study of retained intravitreal lens fragments after phacoemulsification, Yeo $e a^{23}$ found that there was significantly less inflammatory cell activity in eyes receiving early pars plana vitrectomy within 1 week. Later removal was associated with persistently elevated intraocular pressure and poorer visual outcome.

Therefore, early vitrectomy at the time of cataract surgery may prevent the development of secondary glaucoma by limiting lens-induced intraocular inflammation. This is particularly relevant in those eyes with pre-existing compromised outflow facility or various optic neuropathies.

Similarly, lens-induced prolonged intraocular inflammation may theoretically increase vitreoretinal traction and cause retinal detachment. ${ }^{7}$ A trend of increased incidence of retinal detachment in eyes of delayed vitreous surgery was observed by Margherio et al..$^{13}$ The commonest postoperative complication in our series was retinal detachment that occurred in three patients (10\%). A slightly higher rate of $18 \%$ was reported by Kageyama $e t a l^{5}$ in which vitrectomy was performed on the same setting of cataract surgery. This rate of retinal detachment is within the range reported in other studies in which vitrectomy was performed later for retained lens fragment, which ranged from 0 to $21.5 \%$. $^{6-17,19,20,21,24,25}$ This suggests that early vitrectomy does not prevent the problem of development of retinal detachment. The reattachment rate for retinal detachment after vitrectomy for retained lens fragment is 
usually favourable, but visual outcomes are often poor due to other comorbidities particularly cystoid macular oedema. ${ }^{25}$ Nonexcessive manipulation during the cataract operation, and appropriate manoeuvre during the vitrectomy procedure are of utmost importance in preventing this complication. Kapusta et al ${ }^{11}$ reported no retinal detachment in their series, attributing to the fact that cataract surgeons in their institution are discouraged from attempting to retrieve the nuclear fragment from deep within the vitreous cavity.

Cystoid macular oedema is another complication associated with lens-induced inflammation and has been found to be a major cause for poor final vision after surgery for retained intravitreal fragments. ${ }^{8,13-15}$ Margherio et $a l^{13}$ found that $27 \%$ of patients developed postoperative cystoid macular oedema after vitrectomy as a late postoperative complication. When vitrectomy was performed on the same setting of cataract surgery, Kageyama et $a l^{5}$ reported a lower rate of postoperative cystoid macular oedema of $12 \%$. In our series, none of the patients developed cystoid macular oedema postoperatively and this is similar to the findings by Kim et $a l^{8}$ in which none of the eight eyes, which underwent vitrectomy on the same day as the complicated cataract surgery, developed postoperative cystoid macular oedema. Early vitrectomy may therefore have a role in reducing the incidence of postoperative cystoid macular oedema by minimising lens-induced inflammation.

We believe that with adequate support from the vitreoretinal services and proper preoperative counselling, this approach not only saves the patient from another operation and associated anaesthetic risk, but also possibly shortens the hospital stay and hastens the visual recovery. We advocate thorough explanation and discussion with patients in the possibility of this consecutive procedure well before cataract operation.

The main limitation of our study is being retrospective in nature. Nevertheless, our study demonstrated that vitrectomy performed at the same setting of cataract surgery for retained lens fragments is a viable option and may decrease the risk of secondary glaucoma and cystoid macular oedema. Further prospective clinical trial in this area may provide us with more insight in determining the optimal timing of vitrectomy. However, it will be rather difficult to conduct a prospective study due to the low incidence of retained lens fragment as well as the lack of immediate vitreoretinal service support in many circumstances.

\section{References}

1 Leaming DV. Practice styles and preferences of ASCRS members - 1994 survey. J Cataract Refract Surg 1995; 21: 378-385.
2 Pingree MF, Crandall AS, Olson RJ. Cataract surgery complications in 1 year at an academic institution. J Cataract Refract Surg 1999; 25: 705-708.

3 Pande M, Dabbs TR. Incidence of lens matter dislocation during phacoemulsification. J Cataract Refract Surg 1996; 22: 737-742.

4 Aasuri MK, Kompella VB, Majji AB. Risk factors for and management of dropped nucleus during phacoemulsification. J Cataract Refract Surg 2001; 27: 1428-1432.

5 Kageyama T, Ayaki M, Ogasawara M, Asahiro C, Yaguchi S. Results of vitrectomy performed at the time of phacoemulsification complicated by intravitreal lens fragments. Br J Ophthalmol 2001; 85: 1038-1040.

6 Gilliland GD, Hutton WL, Fuller DG. Retained intravitreal lens fragments after cataract surgery. Ophthalmology 1992; 99: 1263-1267.

7 Monshizadeh R, Samiy N, Haimovici R. Management of retained intravitreal lens fragments after cataract surgery. Surv Ophthalmol 1999; 43: 397-404.

8 Kim JE, Flynn Jr HW, Smiddy WE, Murray TG, Rubsamen PE, Davis JL et al. Retained lens fragments after phacoemulsification. Ophthalmology 1994; 101: 1827-1832.

9 Blodi BA, Flynn HW, Blodi CF, Folk JC, Daily MJ. Retained nuclei after cataract surgery. Ophthalmology 1992; 99: 41-44.

10 Borne MJ, Tasman W, Regillo C, Malecha M, Sarin L. Outcomes of vitrectomy for retained lens fragments. Ophthalmology 1996; 103: 971-976.

11 Kapusta M, Chen JC, Lam WC. Outcomes of dropped nucleus during phacoemulsification. Ophthalmology 1996; 103: 1184-1187.

12 Vilar NF, Flynn Jr HW, Smiddy WE, Murray TG, Davis JL, Rubsamen PE. Removal of retained lens fragments after phacoemulsification reverses secondary glaucoma and restores visual acuity. Ophthalmology 1997; 104: 787-792 discussion by HR McDonald, pp. 791-792.

13 Margherio RR, Margherio AR, Pendergast SD. Vitrectomy for retained lens fragments after phacoemulsification. Ophthalmology 1997; 104: 1426-1432.

14 Al-Khaier A, Wong D, Lois N, Cota N, Yang YC, Groenewald C. Determinants of visual outcome after pars plana vitrectomy for posteriorly dislocated lens fragments in phacoemulsification. J Cataract Refract Surg 2001; 27: 1199-1206.

15 Rossetti A, Doro D. Retained intravitreal lens fragments after phacoemulsification: complications and visual outcome in vitrectomized and nonvitrectomized eyes. J Cataract Refract Surg 2002; 28: 310-315.

16 Olsson RB, Ritland JS, Bjornsson OM, Syrdalen P, Eide N, Overgard R. A retrospective study of patients with retained nuclear fragments after cataract extraction. Acta Ophthalmol Scand 2000; 78: 677-679.

17 Tommila P, Immonen I. Dislocated nuclear fragments after cataract surgery. Eye 1995; 9: 437-441.

18 Terasaki H, Miyake Y, Miyake K. Visual outcome after management of a posteriorly dislocated lens nucleus during phacoemulsification. J Cataract Refract Surg 1997; 23: 1399-1403.

19 Oruc S, Kaplan HJ. Outcome of vitrectomy for retained lens fragments after phacoemulsification. Ocul Immunol Inflamm 2001; 9: 41-47.

20 Hansson L, Larsson J. Vitrectomy for retained lens fragments in the vitreous after phacoemulsification. J Cataract Refract Surg 2002; 28: 1007-1011. 
21 Kwok AK, Li KK, Lai TY, Lam DS. Pars plana vitrectomy in the management of retained intravitreal lens fragments after cataract surgery. Clin Exp Ophthalmol 2002; 30: 399-403.

22 Wilkinson CP, Green WR. Vitrectomy for retained lens material after cataract extraction. The relationship between histopathologic findings and the time of vitreous surgery. Ophthalmology 2001; 108: 1633-1637.

23 Yeo LM, Charteris DG, Bunce C, Luthert PJ, Gregor ZJ. Retained intravitreal lens fragments after phacoemulsification: a clinicopathological correlation. $\mathrm{Br} J$ Ophthalmol 1999; 83: 1135-1138.

24 Scott IU, Flynn Jr HW, Smiddy WE, Murray TG, Moore JK, Lemus DR et al. Clinical features and outcomes of pars plana vitrectomy in patients with retained lens fragments. Ophthalmology 2003; 110: 1567-1572.

25 Moore JK, Scott IU, Flynn Jr HW, Smiddy WE, Murray TG, Kim JE et al. Retinal detachment in eyes undergoing pars plana vitrectomy for removal of retained lens fragments. Ophthalmology 2003; 110: 709-713. 